\title{
Maternal anaemia and its impact on perinatal outcome in a tertiary care hospital in Pakistan
}

F.W. Lone, ${ }^{1}$ R.N. Qureshi ${ }^{1}$ and F. Emmanuel ${ }^{2}$

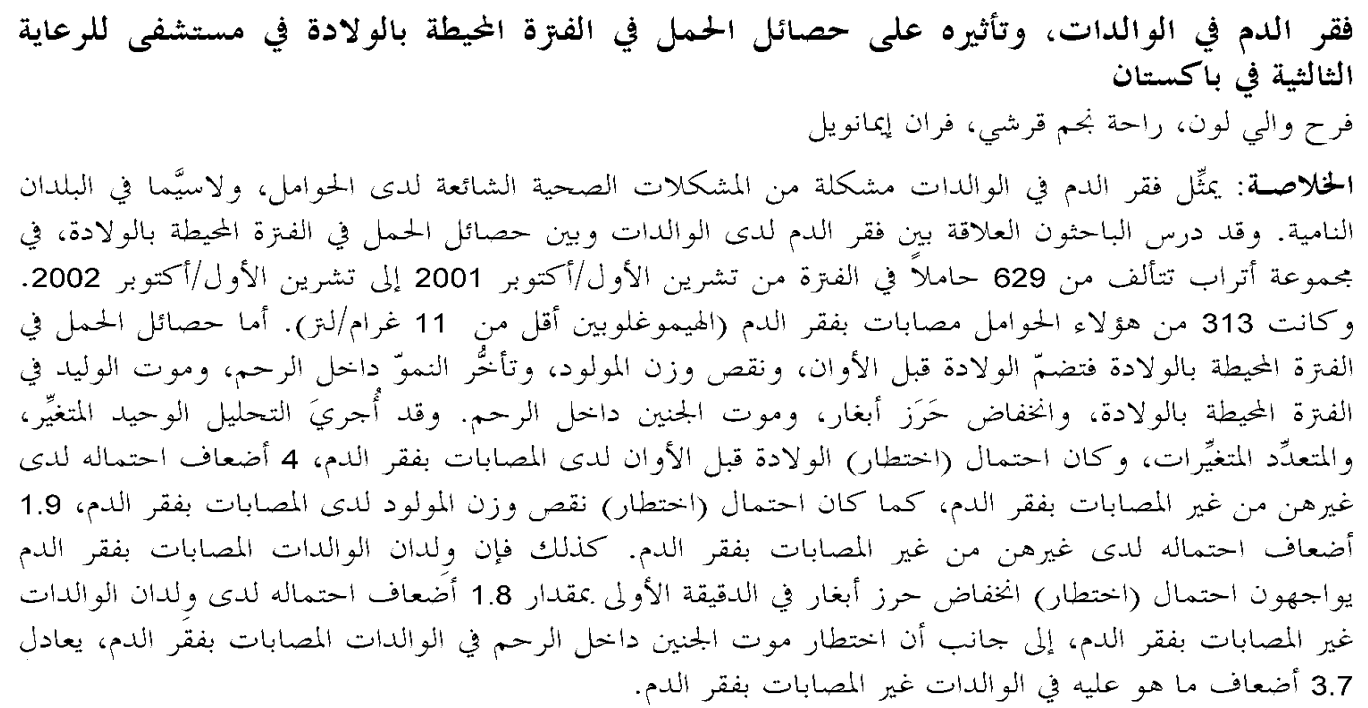

ABSTRACT Maternal anaemia is a common problem in pregnancy, particularly in developing countries. We investigated the relationship between maternal anaemia and perinatal outcome in a cohort of 629 pregnant women from October 2001 to 2002. Of these, 313 were anaemic (haemoglobin < 11 g/L). Perinatal outcomes included preterm delivery, low birth weight, intrauterine growth retardation, perinatal death, low Apgar scores and intrauterine fetal death. Univariate and multivariate analyses were performed. The risk of preterm delivery and low birth weight among the anaemic women was 4 and 1.9 times more respectively than the non-anaemic women. The neonates of anaemic women also had 1.8 times increased risk having low Apgar scores at 1 minute and there was a 3.7 greater risk of intrauterine fetal death among the anaemic women than the non-anaemic women.

\begin{abstract}
L'anémie maternelle et son impact sur l'issue périnatale dans un hôpital de soins tertiaires au Pakistan

RÉSUMÉ L'anémie maternelle est un problème courant durant la grossesse, notamment dans les pays en développement. Nous avons examiné la relation entre l'anémie maternelle et l'issue périnatale dans une cohorte de 629 femmes enceintes, d'octobre 2001 à 2002. Parmi celles-ci, 313 étaient anémiques (hémoglobine $<11 \mathrm{~g} / \mathrm{L}$ ). Les issues périnatales comprenaient la naissance prématurée, le faible poids de naissance, le retard de croissance intra-utérine, le décès périnatal, le faible score d'Apgar et le décès in utero du fœtus. On a procédé à une analyse univariée et multivariée. Le risque de prématurité et d'insuffisance pondérale à la naissance est respectivement 4 fois et 1,9 fois plus élevé chez les femmes anémiques que chez les femmes non anémiques. Les nouveau-nés des femmes anémiques avaient en outre un risque 1,8 fois supérieur d'avoir un faible score d'Apgar à 1 minute et il y avait un risque de décès in utero du foetus 3,7 fois plus élevé chez les femmes anémiques que chez les femmes non anémiques.
\end{abstract}

${ }^{1}$ Department of Obstetrics and Gynaecology; ${ }^{2}$ Department of Community Health Sciences, Aga Khan University, Karachi, Pakistan.

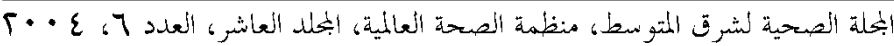




\section{Introduction}

It has long been recognized that anaemia is a major public health problem especially among poorer segments of the population in developing countries such as India, Pakistan and Bangladesh [1]. Anaemia is one of the most prevalent nutritional deficiency problems afflicting pregnant women [2], defined by the World Health Organization as haemoglobin levels of $\leq 11 \mathrm{~g} / \mathrm{dL}$ [33]. Maternal anaemia in pregnancy is commonly considered a risk factor for poor pregnancy outcome and can result in complications that threaten the life of both mother and fetus [4]. However, the extent to which maternal anaemia affects maternal and neonatal health is still uncertain. Some studies have demonstrated a strong association between low haemoglobin before delivery and adverse outcomes [5] while others have not found a significant association [6].

The prevalence of anaemia in pregnancy varies considerably because of differences in, for example, socioeconomic conditions, lifestyles and health-seeking behaviours across different cultures. Prior research in Pakistan has documented iron deficiency as the leading cause of anaemia in pregnancy [6]. The effects of anaemia on pregnancy outcome in Pakistan have not been evaluated systematically in randomized, prospective intervention trials that include a sufficient number of iron-deficient women, while controlling for possible confounding factors. Nonetheless, the pattern of anaemia in Pakistan and other Asian countries indicates that it is an area of public health that needs attention.

Thus the aim of this study was to investigate the relationship between maternal anaemia and perinatal outcome in Pakistan.

\section{Methods}

In this cohort study, the association of multiple effects of anaemia on perinatal outcome were studied among the pregnant women attending the Obstetrics Department of the Aga Khan University Hospital from October 2001 to October 2002.

A total number of 2975 women were delivered during the study year. From these, we included all the women who fulfilled the following inclusion criteria:

- attended the outpatient clinic before 16 weeks of gestation

- age 16 years and above

- singleton pregnancy

- had complete medical records of the pregnancy.

Women with a past history of preterm delivery, obstetric complications or medical illnesses, except anaemia, were excluded.

Exposure (anaemia) was defined as haemoglobin level of $<11 \mathrm{~g} / \mathrm{dL}$ in labour and on 2 previous occasions in the current pregnancy. Women were interviewed in the local language (Urdu) on the second day of delivery and the data from the interview and medical records were recorded on a pre-designed questionnaire. During antenatal care, height and weight were recorded at each antenatal visit and haemoglobin level was measured at the first antenatal visit, at 28 to 32 weeks, at 33 to 37 weeks and in labour. Women who had haemoglobin $<11$ $\mathrm{g} / \mathrm{dL}$ were given oral iron; those with haemoglobin $<7 \mathrm{~g} / \mathrm{dL}$ in the third trimester were given either blood transfusion or intravenous iron therapy. Information regarding gestational age at delivery, perinatal outcome (live birth, stillbirth, intrauterine death), intrauterine growth retardation (IUGR) and the type of IUGR were noted 
from the medical records. Weight of the neonate and Apgar score at 1 and 5 minutes were also recorded.

One month after delivery, the same interviewer (a medical student) conducted a repeat interview with the mother and reviewed the medical records of the neonate. Health status of the neonate, and perinatal mortality and its cause were documented.

The data were analysed with SPSS, version 7.5. Frequencies were determined; Levene's test was applied to measure equality of variances and the $t$-test used to compare means. Univariate analysis was performed and also multivariate analysis was undertaken to control for confounding factors using multiple logistic regression for dependent variables.

Results are expressed as means, standard deviations (SD), adjusted relative risk and $95 \%$ confidence intervals $(95 \% \mathrm{CI})$.

\section{Results}

A total of 629 women fulfilled the inclusion criteria, 313 in the anaemic group and 316 were in the non-anaemic group. The study was explained to the women and they all agreed to participate. Only 22 women were lost to follow-up after the first interview.

Table 1 shows the demographic and socioeconomic characteristics of the 2 groups. The mean age of the anaemic women was $26.85(\mathrm{SD}=4.77)$ years as compared with $27.08(\mathrm{SD}=4.65)$ years in the non-anaemic group. Most of the women in both groups were Muslims, urban dwellers and spoke the national language Urdu. There were no statistically significant differences between the groups in terms of educational level (most up to Grade 10; 15-16 years of age), employment status (most were housewives), fam-

\begin{tabular}{|c|c|c|c|c|}
\hline \multirow{2}{*}{ Variable } & \multicolumn{2}{|c|}{$\begin{array}{l}\text { Anaemic } \\
(n=313)\end{array}$} & \multicolumn{2}{|c|}{$\begin{array}{c}\text { Non-anaemic } \\
\quad(n=316)\end{array}$} \\
\hline & No. & $\%$ & No. & $\%$ \\
\hline $\begin{array}{l}\text { Age (years) } \\
\text { mean (SD) }\end{array}$ & \multicolumn{2}{|c|}{$26.85(4.77)$} & \multicolumn{2}{|c|}{$27.08(4.65)$} \\
\hline Maternal education & & & & \\
\hline$(15-16$ years of age & e) 264 & 84.3 & 288 & 91.1 \\
\hline Above grade 10 & 49 & 15.7 & 28 & 8.9 \\
\hline \multicolumn{4}{|l|}{ Employment status } & \\
\hline the home & 265 & 84.7 & 263 & 83.2 \\
\hline Housewife & 48 & 15.3 & 53 & 16.8 \\
\hline \multicolumn{5}{|l|}{ Family structure } \\
\hline Extended & 202 & 64.5 & 184 & 58.2 \\
\hline Nuclear & 111 & 35.5 & 132 & 41.8 \\
\hline \multicolumn{5}{|l|}{$\begin{array}{l}\text { Monthly income } \\
\text { (Pakistani rupees) }^{a}\end{array}$} \\
\hline$<20000$ & 114 & 36.4 & 118 & 37.3 \\
\hline $20000-30000$ & 99 & 31.6 & 117 & 37.0 \\
\hline $30000-50000$ & 82 & 26.2 & 70 & 22.2 \\
\hline$>50000$ & 18 & 5.8 & 11 & 3.5 \\
\hline
\end{tabular}

aUS\$ 1 = 58 Pakistani rupees. $S D=$ standard deviation.

ily structure (most lived in extended families) and monthly income (most had < 300000 Pakistani rupees). Thus the 2 groups were well matched.

Table 2 shows the univariate analysis of perinatal outcome variables in the two groups. Risk of preterm delivery $(<37$ weeks) was 4 times greater among the anaemic women with a statistically significant association (95\% CI: 2.5-6.3). There was a 2.2 times and 1.9 times increased risk of low birth weight (LBW) $(95 \% \mathrm{CI}$ : 1.3-3.7) and IUGR (95\% CI: $1.1-3.3)$ respectively in the anaemic women. The risk

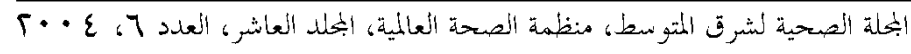




\begin{tabular}{|c|c|c|c|c|}
\hline Variable & $\begin{array}{l}\text { Anaemic } \\
(n=313)\end{array}$ & $\begin{array}{c}\text { Non-anaemic } \\
(n=316)\end{array}$ & $\begin{array}{c}\text { Adjusted } \\
\text { relative risk }\end{array}$ & $95 \% \mathrm{Cl}$ \\
\hline \multicolumn{5}{|c|}{ Premature birth } \\
\hline Yes & 79 & 20 & 4.0 & $2.5-6.3$ \\
\hline No & 234 & 296 & 1.0 & \\
\hline \multicolumn{5}{|c|}{ Low birth weight } \\
\hline Yes & 42 & 19 & 2.2 & $1.3-3.7$ \\
\hline No & 271 & 297 & 1.0 & \\
\hline \multicolumn{5}{|l|}{ IUGR } \\
\hline Yes & 41 & 18 & 1.9 & $1.1-3.3$ \\
\hline No & 272 & 298 & 1.0 & \\
\hline \multicolumn{5}{|c|}{ Perinatal mortality } \\
\hline Yes & 6 & 2 & 3.2 & $0.7-14.6$ \\
\hline No & 307 & 314 & 1.0 & \\
\hline \multicolumn{5}{|c|}{ Low Apgar at $1 \mathrm{~min}$} \\
\hline Yes & 32 & 16 & 2.1 & $1.2-3.7$ \\
\hline No & 281 & 300 & 1.0 & \\
\hline \multicolumn{5}{|c|}{ Low Apgar at 5 min } \\
\hline Yes & 27 & 17 & 1.7 & $1.0-3.1$ \\
\hline No & 286 & 299 & 1.0 & \\
\hline \multicolumn{5}{|c|}{$\begin{array}{l}\text { Intrauterine fetal } \\
\text { death }\end{array}$} \\
\hline Yes & 5 & 2 & 2.5 & $0.7-13.0$ \\
\hline No & 308 & 314 & 1.0 & \\
\hline
\end{tabular}

$\mathrm{Cl}=$ confidence interval .

IUGR = intrauterine growth retardation.

of perinatal mortality was 3.2 times greater among the anaemic women but this was not statistically significant $(95 \%$ CI: $0.7-$ 14.6). The risk of an Apgar score $\leq 5$ at 1 minute and $\leq 7$ at 5 minutes in the anaemic women was 2.1 (95\% CI: $1.2-3.7)$ and 1.7 (95\% CI: $1.0-3.1)$ respectively greater that the non-anaemic women. The anaemic women were also at a 2.5 times increased risk of intrauterine fetal death compared with the non-anaemic group but this was not statistically significant $(95 \%$ CI: $0.7-$ 13.0).
Table 3 shows the multivariate analysis of the sample. The anaemic group was at a 4 times increased risk of having preterm delivery $(95 \%$ CI: $2.5-6.3)$. The risk of LBW in the anaemic group was 1.9 times higher (95\% CI: $1.0-3.4)$ than the nonanaemic group. As regards perinatal outcome, the anaemic group had a 1.8 times higher risk of giving birth to a baby with an Apgar score $\leq 5$ at 1 minute (95\% CI: $1.2-$ 3.7). The risk of intrauterine death was 3.7 times greater in the anaemic women $(95 \%$ CI: 0.86-14.6). 


\begin{tabular}{|c|c|c|}
\hline Variable & $\begin{array}{l}\text { Adjusted } \\
\text { relative risk }\end{array}$ & $95 \% \mathrm{Cl}$ \\
\hline \multicolumn{3}{|c|}{ Premature birth } \\
\hline Yes & 4.0 & $2.5-6.3$ \\
\hline No & 1.0 & \\
\hline \multicolumn{3}{|c|}{ Low birth weight } \\
\hline Yes & 1.9 & $1.0-3.4$ \\
\hline No & 1.0 & \\
\hline \multicolumn{3}{|c|}{ Low Apgar at $1 \mathrm{~min}$} \\
\hline Yes & 1.8 & $1.2-3.7$ \\
\hline No & 1.0 & \\
\hline \multicolumn{3}{|c|}{ Intrauterine fetal death } \\
\hline Yes & 3.7 & $0.86-14.6$ \\
\hline No & 1.0 & \\
\hline
\end{tabular}

$\mathrm{Cl}=$ confidence interval .

\section{Discussion}

Anaemia is a common problem in pregnant women in developing countries. The pregnancy outcomes show a variation depending upon the type of anaemia. Studies have demonstrated differences in outcomes in iron deficiency as compared to physiological anaemia of pregnancy [7]. In populations where the rate of anaemia is low among non-pregnant women, the primary cause of anaemia during pregnancy is likely to be plasma volume expansion, and this type of anaemia is not associated with negative birth outcomes [8]. Maternal haemoglobin values during pregnancy are associated with LBW and preterm birth in a U-shaped relationship with high rates of LBW at low and high concentrations of maternal haemoglobin. However, some of this association may result from using "lowest haemoglobin" rather than a haemoglobin value controlled for the stage of pregnancy.
A similar U-shaped association is likely to be found between maternal haemoglobin and perinatal mortality, but the data to establish this association are insufficient [9]. As it is estimated that about 7.3 million perinatal deaths occur annually in the world, mostly in developing countries [10], one could assume many of these deaths could be prevented by correcting maternal anaemia.

Prematurity and birth anoxia are the main causes of perinatal deaths in Pakistan. This is in great part because of poor resuscitation facilities and neonatal care in the country, putting premature babies at greater risk of perinatal death. In our study sample, although prematurity was the leading cause of perinatal death, it was lower than the perinatal mortality in other hospitals of Pakistan [11,12] probably due to the better resuscitation and neonatal care facilities in our hospital.

Severe anaemia $(<8 \mathrm{~g} / \mathrm{dL})$ has been reported to be associated with birth weight values that are 200-400 g lower than in women with higher ( $>10 \mathrm{~g} / \mathrm{dL})$ haemoglobin values, but in that study other factors that might also have contributed to both LBW and the severity of anaemia were not excluded [13].

Maternal infections during pregnancy are a well-known risk factor for preterm labour and the examination of amniotic fluid or placental membranes has shown the presence of bacteria or inflammatory cytokines [14]. The relationship between anaemia and infections may be due to adverse effects of anaemia on immune function as a result of alterations in the proliferation of $\mathrm{T}$ and $\mathrm{B}$ lymphocytes thus reducing the killing activity of phagocytes and neutrophils, and lowering the bactericidal and natural killer cell activity [15]. Lymphocyte stimulation indices have also

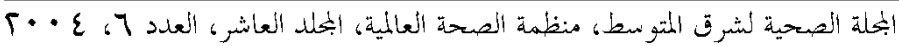


been found to be lower in anaemic women [16].

Research has been conducted to understand how anaemia may predispose to preterm labour either directly or indirectly due to increased risk of infection. The direct effect is related to increased synthesis of corticotrophin-releasing hormone $(\mathrm{CRH})$ as a result of tissue hypoxia [17]. These raised levels can induce maternal and fetal stress [18], and thus produce a risk factor for preterm labour, pregnancy-induced hypertension and premature rupture of the membranes. CRH also increases fetal cortisol production, which may inhibit longitudinal growth of the fetus [19]. An alternative mechanism could be that iron deficiency increases oxidative damage to erythrocytes in the feto-placental unit, which can stimulate the production of $\mathrm{CRH}$. These abnormalities in the regulation of $\mathrm{CRH}$ and the production of inflammatory cytokines inhibit the activity of natural killer cells both in vivo and in vitro.

Our results show the association of maternal anaemia in pregnancy with increased risk of delivery of premature and LBW babies, intrauterine death and low Apgar score at 1 minute. Neonates of anaemic women were also found to be at increased risk of perinatal mortality. These deaths were commonly found to be due to prematurity and sepsis. Since our study was conducted in a tertiary care hospital and the majority of women in Pakistan deliver at home, it is expected that the burden of anaemia and its effect on pregnancy outcome is much greater outside the hospital setting.

Anaemia is one of the main nutritional deficiency disorders affecting a large proportion of the population, not only in devel- oping but also in industrialized countries. In the developing countries, poverty, gender bias and lack of education about the importance of a balanced and iron-rich diet contribute to anaemia. The high prevalence of iron and other micronutrient deficiencies among women before and during pregnancy in developing countries is of concern and maternal anaemia is still a cause of considerable perinatal mortality and morbidity [20]. The improvement in the industrialized world is due largely to more effective diagnosis and treatment of anaemia. Although bringing about a change and introducing interventions at an early age in women remain a challenge in developing countries, efforts must be made to address the problem through strategies such as fortification and periodic supplementation and counselling of women of the risks of anaemia in pregnancy [20]. This may help to reduce the manifestation of iron deficiency, improve public health and thus reduce maternal and neonatal morbidity and mortality.

Additional studies on pregnant women are needed in which appropriate measures of immune function are evaluated in response to iron supplementation. Furthermore, little is known concerning the effects of maternal iron status during pregnancy on subsequent health and development of the infant and on the quality of life of the mother. These areas warrant detailed research. Finally, other nutritional deficiencies have also been proposed to have an impact on maternal and fetal outcome, e.g. niacin and zinc deficiency. These need to be studied in detail so that when further research is being done on iron deficiency anaemia, the effect of such confounders can be ameliorated. 


\section{References}

1. The prevalence of anaemia in women: a tabulation of available information, 2nd ed. Geneva, World Health Organization, 1992.

2. Thangaleela T, Vijayalakshmi P. Impact of anaemia in pregnancy. Indian journal of nutrition and dietetics, 1994, 31:92516.

3. Thangaleela T, Vijayalkshmi P. Prevalence of anaemia in pregnancy. Indian journal of nutrition and dietetics, 1994, 31:26-2.

4. Gregory P, Taslim A. Health status of the Pakistani population: a health profile and comparison with the United States. American journal of public health, 2001, 91:93-8.

5. Iron deficiency anemia: re-examining the nature and magnitude of the public health problem. Proceedings of a conference. May 21-24, 2000. Belmont, Maryland, USA. Journal of nutrition, 2001, 131(2S-2):563S-703S.

6. Karim SA et al. Anaemia in pregnancyits cause in the underprivileged class of Karachi. Journal of the Pakistan Medical Association, 1994, 44:90-2.

7. Duthie SJ et al. A case-controlled study of pregnancy complicated by severe maternal anaemia. Australian \& New Zealand journal of obstetrics \& gynaecology, 1991, 31:125-7.

8. Whittaker PG, Macphail S, Lind T. Serial hematologic changes and pregnancy outcome. Obstetrics and gynecology, 1996, 88:33-9.

9. Verma KC, Dhar G. Relationship of maternal anaemia, birth weight and perinatal mortality: a hospital study. Indian pediatrics, 1976, 13:439-41.

10. Shazia T, Faheem S, Saad R. Perinatal mortality: A survey. Pakistan journal of obstetrics and gynecology, 1994, 7(2):18.
11. Rana S. Coordinated maternity services. Pakistan journal of obstetrics and gynecology, 1994, 4(1):1-19.

12. Saad R. Perinatal mortality in Pakistan: $A$ survey. Pakistan journal of obstetrics and gynecology, 1990, 3(1):13-21.

13. Steer $\mathrm{P}$ et al. Relationship between maternal haemoglobin concentration and birth weight in different ethnic groups. British medical journal, 1995, 310:48991.

14. Amici $D$ et al. A natural killer cell activity and delivery: possible influence of cortisol and anesthetic agents. A study on newborn cord blood. Biology of the neonate, 1999, 76:348-54.

15. Hooton TM et al. A prospective study of risk factors for symptomatic urinary tract infection in young women. New England journal of medicine, 1996, 335:468-74.

16. Stamey TA, Timothy MM. Studies of introital colonization in women with recurrent urinary infections. The role of vaginal $\mathrm{pH}$. Journal of urology, 1975, 114:261-3.

17. Kurki T et al. Bacterial vaginosis in early pregnancy and pregnancy outcome. $\mathrm{Ob}$ stetrics and gynecology, 1992, 80:1737.

18. Mikhail MS, Anyaegbunam A. Lower urinary tract dysfunction in pregnancy: a review. Obstetrical \& gynecological survey, 1995, 50:675-83.

19. Goldenberg $\mathrm{RL}$ et al. Plasma ferritin and pregnancy outcome. American journal of obstetrics and gynecology, 1996, 175: 1356-9.

20. Cutner A, Bead R, Harding J. Failed response to treat anaemia in pregnancy: reasons and evaluation. Journal of obstetrics and gynecology, 1999, (suppl.): S23-7.

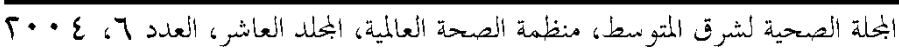

